\title{
A Feasibility Study on the Research Infrastructure Projects for enhancing the ICT Devices Industry Reliability using AHP
}

\author{
Dae Ho Kim \\ Division of Service Management, Mokwon University, \\ School of Social Science \#E-422, DoanBuk-Ro 88, Seo-Ku, Daejeon, Korea \\ mis@acm.org
}

\begin{abstract}
The research infrastructure project of ICT devices industry reliability is aimed to secure and establish the reliability of ICT devices industry, reinforce the competitiveness of domestic ICT device companies and expand their growth power. To improve the quality of domestic ICT devices and help excellent domestic devices land on foreign markets, it is required to secure expensive testing environment for the provision of test evaluation services and the governmental support environment for the development of test technology and test evaluation service. These days it is necessary to enhance and expand test evaluation services for the domestic ICT devices developed by small and mediumsized companies (SMCs) such as benchmark test, certification test, performance verification test, delivery test, and the development assistances that are needed for domestic ICT devices SMCs to enter into the global market. The purpose of this study is to implement the feasibility analysis on this project. Therefore this study is using this AHP method which has established specific analysis processes and can quickly confirm the validity of analysis results for calculating the weights of the evaluation criteria. And in this study the comprehensive score by AHP analysis results is 0.861 and it shows that the implementation of this project is feasible.
\end{abstract}

Keywords: ICT Device Industry Reliability, ICT Research Infrastructure Project, Feasibility Analysis. Analytic Hierarchy Process

\section{Introduction}

The research infrastructure project of ICT device industry reliability is one of IT and communication research infrastructure projects. It is aimed to help establish the research infrastructure for the ICT device industry reliability, reinforce the competitiveness of domestic ICT device companies and expand their growth engine [1].

To improve the quality of domestic ICT device and help excellent domestic devices land on foreign markets, it is required to secure expensive testing environment for the provision of test evaluation services and the governmental support environment for the development of test technology and test evaluation service.

Test evaluation services, including benchmark test, certification test, performance verification test, delivery test, and the development support for the domestic ICT devices developed by small and medium companies (SMCs), should be enhanced and expanded. In addition, the government support is essential for establishing the infrastructure of test evaluation.

Since the establishment of performance evaluation test environment to support the commercialization of ICT devices of SMCs and the improvement of the product quality has the characteristic of public goods, government support is indispensable. Support for bottleneck technology and test evaluation technology, establishing test 
environment and devices require large amounts of investment. And the supports for the commercialization of SMCs products and quality improvement ask for closer services through establishing various test beds and open labs.

The core contents of this project which is to support competitiveness of domestic ICT devices (for example, network equipment, computing equipment, and broadcasting equipment) are 1) the establishment of comprehensive test evaluation environment and the provision of services, 2) the technology validation and the development support strengthening on domestic cloud computing devices with expected growth potential of domestic companies and 3) the establishment of support system for improvement of domestic ICT devices reliability. This study is aimed to carry out the feasibility analysis of this project on the basis of its preliminary planning reports [1].

\section{Analytic Hierarchy Process Method}

Saaty (1980) suggested the analytic hierarchy process (AHP) as a weight calculation method [2]. AHP is a method that conducts pairwise comparison (one to one comparison) for decision-making by stages, dividing the entire processes of the decision-making into seven stages to reach the final decision (weight calculation) [3].

Especially, AHP can increase the rationality and logicality of the decision by conducting consistency ratio analysis to see if the responder is maintaining consistency logically in the analysis process.

Also AHP can be useful in deriving the weight of the evaluation criteria by utilizing the qualitative knowledge of the experts in the fields where the quantitative analysis is difficult.

As the above AHP is a method that organizes, structures, and systemizes the experiences of experts in the decision of the fields where the quantitative approach is difficult, and it is one of the decision methods that is designed to be suited for mathematical model in the decision stages $[4,5]$. In other words, it is one of the decision support methods that support the systematic evaluation on mutually exclusive alternatives when the goals or the evaluation standards for decision are multiple or complex, and it is a multi-criteria decision-making method that includes qualitative elements.

Therefore this study is using this AHP method which has established specific analysis processes and can quickly confirm the validity of analysis results for calculating the weights of the evaluation criteria.

\section{Data Collection}

\subsection{Questionnaire Structure for Data Collection}

The level 1 questionnaire items for collecting the priority data are composed of pairwise comparison to compare the level of significance about the most significant evaluation criteria (technology, policy, and economics), and in the level 2, it is composed of pairwise comparison between criteria to investigate the relative level of significances about detailed criteria (sub-criteria) for each level 1 criteria. The hierarchical structure among evaluation criteria is represented in Figure 1 [6]. 


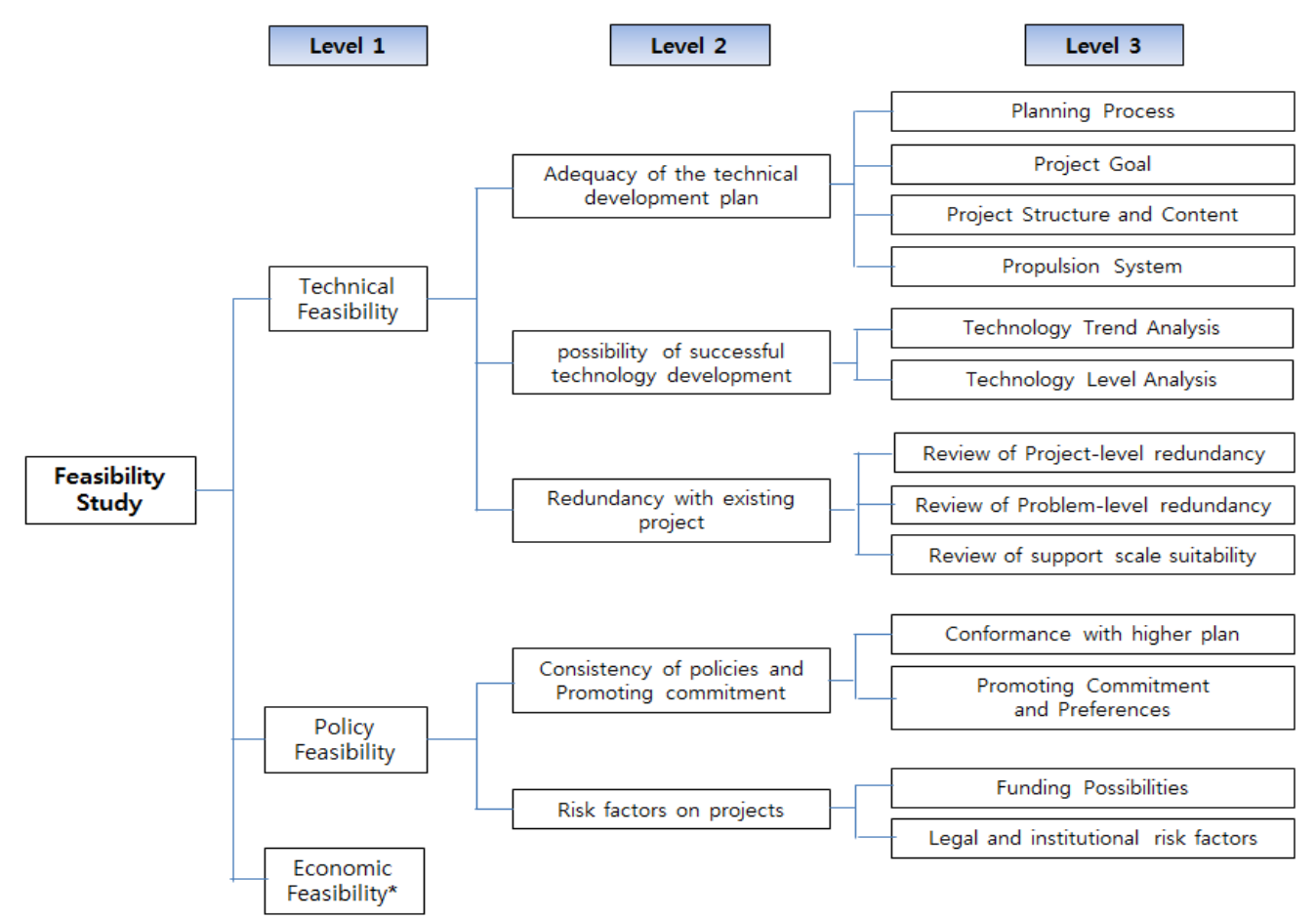

Figure 1. Hierarchical Structure for AHP Analysis on this Project

9 points Likert interval scales were used as the measure of the survey items and the data was marked according to the relative level of significance for each comparison criterion. And each criterion that asks for the pairwise comparison about the criteria of performance evaluation can have one point from 9 point (maximum preference between two criteria) to -9 point (minimum preference between two criteria), where 1 point means the same preference between two criteria, so respondents were requested to mark the point that is considered to be more significant.

\subsection{Selection of Respondents}

The respondents that participated in the final decision of the research and development preliminary feasibility study were researchers of national IT industry promotion agency which is the executive agency and planning committee of the researchers composed by project areas. For the balanced opinion reflection, researchers of the national IT industry promotion agency, and the PD and advisory board members participated in the survey as the respondents. The advisory board groups were divided into three groups such as technology experts group, policy expert group and economy experts group.

\section{Feasibility Analysis using AHP}

\subsection{Hierarchy Analysis on each Evaluation Criterion}

In the general instructions of the preliminary feasibility survey published by the Korea Development Institute, the tolerance of the consistency ratio was set as 0.15 and it is recommended that for responders that exceed 0.15 , response consistency should be increased through feedback process [7]. The survey for this research, a total of six people participated and all evaluators went through the feedback process to increase their response consistency. 


\subsection{The Criteria Analysis in the First Level}

The criteria in the first level are 'Technology Feasibility', 'Policy Feasibility', and 'Economic Feasibility' and the weights of each criterion are as follows:

Table 1. The Weights of each Criterion in the First Level

\begin{tabular}{|c|c|c|c|}
\hline & Technical Feasibility & Policy Feasibility & Economic Feasibility \\
\hline respodent 1 & 0.35 & 0.25 & 0.4 \\
\hline respodent 2 & 0.35 & 0.20 & 0.45 \\
\hline respodent 3 & 0.3 & 0.3 & 0.4 \\
\hline respodent 4 & 0.3 & 0.3 & 0.4 \\
\hline respodent 5 & 0.3 & 0.25 & 0.49 \\
\hline respodent 6 & 0.2 & 0.35 & 0.45 \\
\hline Average & 0.298 & 0.274 & 0.428 \\
\hline
\end{tabular}

The weights of each criterion in the first level, shown in Table 1, show the differences among the respondents in their judgment bases. And it shows that it is the criterion 'Economic Feasibility' which has the highest weight, and the criterion 'Technical Feasibility' is the next one. And it is the criterion 'Policy Feasibility' which has the lowest one.

\subsection{The Criteria Analysis in the Second Level}

In the second level, there are 3 sub-criteria of the Technical Feasibility, and 2 subcriteria of the Political Feasibility. And I analyzed these criteria of Technical Feasibility and of Political Feasibility in this section,

4.3.1 The Sub-criteria Analysis of Technical Feasibility: The criteria of Technical Feasibility are composed of 1) 'the Adequacy of the Technical Development Plan (Plan)', 2) 'the Possibility of Successful Technology Development (Success)', and 3) 'the Redundancy with Existing Project (Redundancy)'. The weights of these criteria are as follows:

Table 2. The Weights of Each Criterion of Technical Feasibility in the Second Level

\begin{tabular}{|c|c|c|c|c|}
\hline & Plan & Success & Redundancy & Weight \\
\hline Plan & 1 & 1.22 & 2.93 & 0.465 \\
\hline Success & & 1 & 2.20 & 0.371 \\
\hline Redundancy & & 1 & 0.164 \\
\hline \multicolumn{5}{|c|}{ C.I. $=0.00$} \\
\hline
\end{tabular}

The weights of these three criteria in the second level are shown in Table 2. The Adequacy of the Technical Development Plan has the highest weight, 0.465, the weight of the possibility of Successful Technology Development is 0.371 , and the weight of the Redundancy with Existing Project is 0.164.

4.3.2 The Sub-criteria Analysis of Policy Feasibility: The criteria of Policy Feasibility are composed of 1) 'the Consistency of Policies and Promoting Commitment 
(Consistency)', and 2) 'the Risk Factors on Projects (Risk)'. The weights of these criteria are as follows:

Table 3. The Weights of Each Criterion of Policy Feasibility in the Second Level

\begin{tabular}{|c|c|c|c|}
\hline & Consistency & Risk & Weights \\
\hline Consistency & 1 & 4.79 & 0.827 \\
\hline Risk & & 1 & 0.173 \\
\hline \multicolumn{4}{|c|}{ C.I. $=0.00$} \\
\hline
\end{tabular}

The weights of these two criteria in the second level are shown in Table 3. The weight of 'the Consistency of Policies' and 'Promoting Commitment' is 0.827, and the one of 'the Risk Factors on Projects' is 0.173.

\subsection{The Third Level Criteria Analysis}

\subsubsection{The Third Level Sub-criteria of the Technical Feasibility}

1) The Sub-criteria of the Adequacy of the Technical Development Plan: There are four sub-criteria of the Adequacy of the Technical Development Plan - 'the Planning Process (Planning)', 'the Project Goal (Goal)', 'the Project Structure and Content (Structure)', and 'the Propulsion System (System)'. The weights of these criteria by the results of the pairwise comparison between these criteria are as follows:

Table 4. The Weights of Each Sub-criterion of the Adequacy of the Technical Development Plan

\begin{tabular}{|c|c|c|c|c|c|}
\hline & Plan & Goal & Structure & System & Weights \\
\hline Plan & 1 & $1 / 2.23$ & $1 / 2.84$ & $1 / 1.42$ & 0.135 \\
\hline Goal & & 1 & $1 / 1.51$ & 1.29 & 0.274 \\
\hline Structure & & & 1 & 1.62 & 0.379 \\
\hline System & & \multicolumn{5}{c|}{ C.I. $=0.00$} \\
\hline \multicolumn{1}{|l}{} \\
\hline
\end{tabular}

The weights of these four criteria in the third level are shown in Table 4. The weights of 'The Planning Process (Planning)', 'the Project Goal (Goal)', 'the Project Structure and Content (Structure)', and 'the Propulsion System (System) are 0.135, 0.274, 0.379, and 0.212 , respectively.

2) The Sub-criteria of the Possibility of Successful Technology Development: There are two sub-criteria of the Possibility of Successful Technology Development - 'the Technology Trend Analysis (Trend Analysis)', and 'the Technology Level Analysis (Level Analysis)'. The weights of these criteria by the results of the pairwise comparison between these criteria are as follows: 
Table 5. The Weights of Each Sub-criterion of the Possibility of Successful Technology Development

\begin{tabular}{|c|c|c|c|}
\hline & Trend Analysis & Level Analysis & Weights \\
\hline Trend Analysis & 1 & 2.05 & 0.673 \\
\hline Level Analysis & \multicolumn{3}{|c|}{ C.I. $=0.00$} \\
\hline & \multicolumn{3}{|c}{0.327} \\
\hline
\end{tabular}

The weights of these two criteria in the third level are shown in Table 5. The weights of 'the Technology Trend Analysis (Trend Analysis)', and 'the Technology Level Analysis (Level Analysis)' are 0.673, and 0.327, respectively.

3) The Sub-criteria of the Redundancy with the Existing Project: There are three sub-criteria of the Redundancy with the Existing Project - 'the Review of the Project-level Redundancy (Project)', 'the Review of the Problem-level Redundancy (Problem)', and 'the Review of the Support Scale Suitability (Scale)'. The weights of these criteria by the results of the pairwise comparison between these criteria are as follows:

Table 6. The Weights of Each Sub-criterion of the Redundancy with the Existing Project

\begin{tabular}{|c|c|c|c|c|}
\hline & Project & Problem & Scale & Weights \\
\hline Project & 1 & 1.20 & $1 / 1.47$ & 0.309 \\
\hline Problem & & 1 & $1 / 1.21$ & 0.291 \\
\hline Scale & & \multicolumn{4}{|c|}{ C.I. $=0.01$} \\
\hline & \multicolumn{4}{|c}{} \\
\hline
\end{tabular}

The weights of these three criteria in the third level are shown in Table 6. The weights of 'the Review of the Project-level Redundancy (Project)', 'the Review of the Problemlevel Redundancy (Problem)', and 'the Review of the Support Scale Suitability (Scale)' are $0.309,0.291$ and 0.400 , respectively.

\subsubsection{The Third Level Sub-criteria of Policy Feasibility}

1) The Sub-criteria of the Consistency of Policies and Promoting Commitment: There are two sub-criteria of the Consistency of Policies and Promoting Commitment 'the Conformance with the Higher Plan (Higher Plan)', and 'the Promoting Commitment and Preferences (Promoting Commitment)'. The weights of these criteria by the results of the pairwise comparison between these criteria are as follows:

\section{Table 7. The Weights of Each Sub-criterion of the Consistency of Policies} and Promoting Commitment

\begin{tabular}{|c|c|c|c|}
\hline & Higher Plan & Promoting Commitment & Weights \\
\hline Higher Plan & 1 & 1.71 & 0.631 \\
\hline Promoting Commitment & & 1 & 0.369 \\
\hline \multicolumn{2}{|c|}{ C.I. $=0.00$} \\
\hline
\end{tabular}

The weights of these two criteria in the third level are shown in Table 7. The weights of 'the Conformance with the Higher Plan (Higher Plan)', and 'the Promoting 
Commitment and Preferences (Promoting Commitment)' are 0.631, and 0.369, respectively.

2) The Sub-criteria of the Risk Factors on Projects: There are two sub-criteria of the Risk Factors on Projects - 'the Funding Possibilities (Funding)', and 'the Legal and Institutional Risk Factors (Risk Factors)'. The weights of these criteria by the results of the pairwise comparison between these criteria are as follows:

Table 8. The Weights of Each Criterion of the Risk Factors on Projects

\begin{tabular}{|c|c|c|c|}
\hline & Funding & Risk Factors & Weights \\
\hline Funding & 1 & 2.17 & 0.685 \\
\hline Risk Factors & & 1 & 0.315 \\
\hline \multicolumn{2}{|c|}{ C.I. $=0.00$} \\
\hline
\end{tabular}

The weights of these two criteria in the third level are shown in Table 8. The weights of these criteria by the weights of 'the Funding Possibilities (Funding)', and 'the Legal and Institutional Risk Factors (Risk Factors)' are 0.685, and 0.315, respectively.

\subsection{Overall Hierarchical Criteria Weights}

The hierarchal structure of the evaluation items about the project is composed of a total of three levels, and the first level weight was calculated through the pairwise comparison. Evaluation item weight calculation results by each level are represented in the table 9 .

Table 9. The Weights of each Criterion

\begin{tabular}{c|c|c|c}
\hline Criteria & Level 1 & Level 2 & Level 3 \\
\hline Technical Feasibility & $\mathbf{0 . 2 9 8}$ & & \\
\hline $\begin{array}{c}\text { Adequacy of technical development } \\
\text { plan }\end{array}$ & & 0.139 & \\
\hline Planning Process & & & 0.019 \\
\hline Project Goal & & 0.111 & 0.038 \\
\hline Project Structure and Content & & & 0.029 \\
\hline $\begin{array}{l}\text { Propulsion System } \\
\text { development }\end{array}$ & & & 0.074 \\
\hline $\begin{array}{l}\text { Technology Trend Analysis } \\
\text { Technology Level Analysis }\end{array}$ & & 0.049 & 0.036 \\
\hline $\begin{array}{c}\text { Ronsistency of policies and } \\
\text { Promoting commitment }\end{array}$ & & & \\
\hline $\begin{array}{l}\text { Redundancy with existing project } \\
\text { redundancy }\end{array}$ & & & 0.020 \\
\hline $\begin{array}{l}\text { Review of support scale suitability } \\
\text { Policy Feasibility }\end{array}$ & & & \\
\hline
\end{tabular}




\begin{tabular}{c|c|c|c} 
Conformance with higher plan & & & 0.143 \\
\hline $\begin{array}{l}\text { Promoting Commitment and } \\
\text { Preferences }\end{array}$ & & & 0.084 \\
\hline Risk factors on projects & & 0.047 & \\
\hline Funding Possibilities & & & 0.032 \\
\hline Legal and institutional risk factors & & & 0.015 \\
\hline Economic Feasibility* & $\mathbf{0 . 4 2 8}$ & & \\
\hline
\end{tabular}

* According to the standard guidelines of $\operatorname{KISTEP}(2011)$ [8], the principle is to not apply the result about the economic feasibility of the project on the comprehensive analysis. And the result of the cost-benefit analysis of this project can be found in $\operatorname{Kim}(2015)$ [9].

\subsection{Decision Whether to Implement the Project}

When weight assignment is completed through pairwise comparison by each criterion, it goes through an affinity measuring process between the alternative that implements the analysis subject business based on each evaluation items and the alternative that gives preference score to the alternative that does not implement. Like the weight sitting by evaluation standards the score grant applied Saaty's nine point scale. The information analyzed into multiple items are converted into a single aggregated score and based on this a final decision is made between business implementation alternative and nonimplementation alternative. The result is represented in Table 10 below and there is consistent opinion that it is feasible to implement this business.

Table 10. The Result of AHP Analysis

\begin{tabular}{c|c|c|c|c|c|c|c|c}
\hline & \multicolumn{2}{|c|}{ Final } & \multicolumn{2}{c|}{$\begin{array}{c}\text { Technical } \\
\text { Feasibility }\end{array}$} & \multicolumn{2}{c|}{$\begin{array}{c}\text { Policy } \\
\text { Feasibility }\end{array}$} & \multicolumn{2}{c}{$\begin{array}{c}\text { Economic } \\
\text { Feasibility }\end{array}$} \\
\cline { 5 - 9 } & Do & $\begin{array}{c}\text { Not } \\
\text { Do }\end{array}$ & Do & $\begin{array}{c}\text { Not } \\
\text { Do }\end{array}$ & Do & $\begin{array}{c}\text { Not } \\
\text { Do }\end{array}$ & Do & $\begin{array}{c}\text { Not } \\
\text { Do }\end{array}$ \\
\hline $\begin{array}{c}\text { Comprehensive } \\
\text { Score }\end{array}$ & 0.861 & 0.139 & 0.842 & 0.158 & 0.844 & 0.156 & 0.886 & 0.114 \\
\hline \# of Responses & 6 & 0 & 6 & 0 & 6 & 0 & 6 & 0 \\
\hline
\end{tabular}

\section{Conclusion}

The decision about the project implementation is made by the comprehensive score by AHP analysis results and if the comprehensive score is above 0.55 , it can be determined that the implementation of a project is feasible. And in this study the comprehensive score of doing this project by AHP analysis results is 0.861 and it shows that this project is feasible.

\section{Acknowledgements}

This study was financially supported by the academic research fund of Mokwon University in 2015 and the National Research Foundation of Korea Grant funded by the Korean Government (NRF-2014S1A3A2044645).

\section{References}

[1] "NIPA", 2014 Planning report on the ICT Research Infrastructure Project, (2013) December.

[2] T. L. Saaty, "The Analytic Hierarchy Process: Planning, Priority Setting", Resource Allocation New York: McGraw-Hill Book Co., (1980). 
[3] Y.-T. Park, "Knowledge Management Technology for the Next Generation of Technological Innovations", Saengneung Publisher, (2007).

[4] T. L. Saaty and L. Vargas, "The Logic of Priorities", PA: RWS Pub., (2001).

[5] M.-S. Yoon and S.-B. Park, "An Empirical Study on the Quality Requirements Priorities of Packaged Software Using the AHP", The Journal of Internet Electronic Commerce Research, vol. 8, no. 2, (2008), pp. 39-60.

[6] D. H. Kim, "An Analytic Structure for the Feasibility Analysis on the Research Infrastructure Projects for the ICT Device Industry Reliability", Advanced Science and Technology Letters, vol. 102, (2015), pp. 15-17.

[7] "KISTEP", A Research on the Standard Guideline for the Preliminary Feasibility Study of R\&D Project, 1st Ed., (2011. 12).

[8] "KISTEP", A Research on the Standard Guideline for the Preliminary Feasibility Study of R\&D Project, 1st Ed., (2011. 12).

[9] D. H. Kim, "A Cost-Benefit Analysis on the Research Infrastructure Project of ICT Device Industry Reliability", Proceedings of the 3rd International Conference on Interdisciplinary Research Theory and Technology, (2015) June 22-25, pp. 25-27, Pattaya, Thailand.

\section{Author}

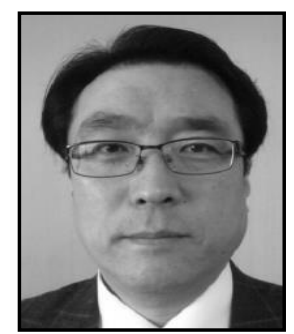

\section{Dae Ho Kim}

Professor, Mokwon University

President, The Society of Mobile Technology

Senior Vice President, Korean Society of Food and Agricultural Information Science

Former President, The Korean Society of Business Venturing 
International Journal of $u-$ and e- Service, Science and Technology Vol.8, No. 9 (2015) 